\title{
Making Mathematical Place Value Meaningful for a Special Needs Student
}

\author{
Estella De Los Santos, Barba Patton \\ University of Houston-Victoria
}

\begin{abstract}
A second grade student's knowledge of mathematical place value was investigated. The overall goal of the work was to improve the student's understanding of place-value concepts for numbers 1 to 999. The information gained from the pre-test was used to develop an individualized education plan. Anodal records were kept on the student's advancement and to monitor the progress. A posttest was given at the conclusion.
\end{abstract}

\section{Introduction}

The student had completed the second grade and this investigation was conducted during the summer break prior to the child entering the third grade. The student has been in inclusion classrooms and has gone to special education classrooms for reading, writing, and mathematics since pre-kindergarten. The student was diagnosed with mild retardation and was performing at the first grade level in the three subjects by the end of the second grade.

According to the student's second-grade classroom teacher, the student was having difficulty with several mathematics concepts including place value. The student had been introduced to several models in mathematics such as counters, touch points, base-ten blocks, a hundred chart, multi-link blocks and the number line. The teacher observed that the student seemed to lose focus when presented with various models. The amount of time the student was able to use any of the models was not available. In this study the researchers addressed place-value concepts.

The research objectives of the study were: 1) to assess the student's knowledge of mathematical place value, 2) to develop an individualized education plan (IEP) and 3) to use the IEP to improve the student's comprehension of place value for numbers 1 to 999 .

\section{Literature Review}

The National Council of Teachers of Mathematics has set as one of the standards for grades Pre-K through $2^{\text {nd }}$ grade: "use multiple models to develop initial understandings of place value and the base-ten numbering system" [1]. The Common Core State Standards Initiative [2] has set understanding twodigit place value for first-grade students and threedigits for second-grade students.

In a 2007 study [3], the researchers investigated understanding of place-value concepts in 128 primary, intermediate, and junior high students. The students had mild disabilities and were grouped according to their achievement level. Six tasks were categorized for each student as being achieved at Level 1, 2, 3, or 4 with Level 4 being the highest level. The four levels assessed understanding and were unique to each of the six tasks. The results showed that a higher percentage of the students in the junior high group attained Level 4 in each of the six tasks. They were followed by the intermediate group and the least number coming from the primary group. "Student performance increased with age, indicating a developmental trend". [3] The results were similar to those of Ross [4], who found that higher performance correlated with age and grade level.

Susan Ross [4, 5, 6] investigated two-digit place value concepts with second through fifth grade students. She proposed five stages in the development of children's understanding of place value. In the first stage, the child is able to read and write two-digit numerals and associate them with the number of objects that they represents; however the child does not know the meaning of the two digits. In the second stage, the child knows that the digit on the right is in the "ones place" and that the digit on the left is in the "tens place"; however the child does not understand the quantity represented by each digit. In the third stage, the child can state that the digit on the left represents " $x$ " number of "tens" and that the digit on the right represents " $y$ " number of "ones"; but does not know that the objects represented by the ones and tens are different objects. In stage four, the child knows that the digit on the left represents sets of ten objects and that the digit on the right represents single objects; however this knowledge is not consistent when presented with non-canonical partitioning of objects. In stage four and five, the children understand part-whole relationships. Stage five differs from stage four in that "the quantity of objects corresponding to each 
digit can be determined even for collections which have been non-canonically partitioned".

Part-Whole relationships can be taught to young children, for example by asking them to count 10 objects. Then divide the objects into two groups such as a group of 4 and 6 and ask them to count the objects again [7]. At first children do not see a pattern in numbers between 10 and 20. They see these as nine additional numbers and words. It is important to use activities were the students can identify fifteen as ten and five more [7]. The use of base ten blocks enhances students' understanding of place value. Resnick and Omanson [8] confirmed Vygotsky's earlier findings of the importance of verbalization.

Miller and Hudson [9] provided several guidelines for helping students with disabilities understand math concepts: use several models to represent the concepts, use appropriate lesson structures for specific concepts, use appropriate mathematical language, use real life applications, and use clear and explicit instruction. These strategies are important for all students to gain a conceptual understanding of mathematics.

\section{Methodology}

Information from the pre-test (a) identified the unique needs of the student, (b) provided guidance in the selection of instructional content and materials, and (c) provided information for the creation of an individualized education plan (IEP). In the study, the student's progress was monitored to evaluate progress of the learning. [10] The study had adequate representation of content, appropriate scope and sequence of the content and developmentally appropriate content to insure accurate measures.

The authors developed two questionnaires, Form A and Form B, modeled after the work of Susan Ross [4, 5, 6]. Form A was used as a diagnostic pretest and Form B was used as a summative evaluation of the individualized instruction. The assessments were used to determine if the student had comprehension of place-value concepts for numbers 1 to 999 .

Based on the results of the diagnostic assessment, the researchers developed an IEP to extend the student's understanding of place value. Formative evaluations were included in the IEP. The instructional models were developmentally appropriate. Each of five instructional sessions was approximately 20 minutes in length. The instructional timeline was individualized and adjusted according to the student's needs.

\section{Results}

The student was given a pretest to assess knowledge of place value for numbers 1-999. Based on the results of the pretest, an individualized education plan (IEP) was designed for the student. Five twenty-minute lessons were provided with the student. A posttest was used to evaluate the student's progress.

\subsection{Pretest}

The student was asked to show representations for 12, 23, 46, and 75 blocks using base-ten blocks. With 12 , the student was able to count from 1 to 12 using the "One" blocks and was then asked to use "Tens" and "Ones" to show 12 blocks. The student miscounted and showed one "Ten" and three "Ones" for 12. On 23, the student used two "Tens" and said, "One, two". The student paused, then added another "Ten" and said, "Three". See Figure 1 below. The student only used the "Ten" blocks to represent 23 and did not understand the difference between the "One" and the "Ten" blocks.

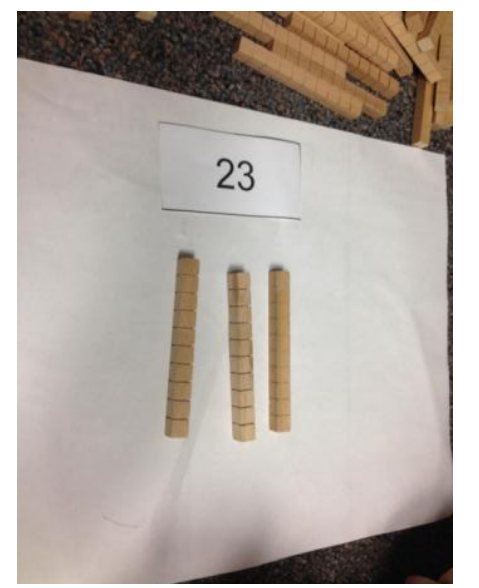

Figure 1. Pretest Representation

There was a similar misconception when showing representations for 46 and 75 . With 46, the student counted four "Tens" and counted, "One, two, three, four". Then the student added two more "Tens" and counted, "Five, six". The final representation for 46 was six "Tens". In showing 75, the student counted seven "Tens" then removed two "Tens" leaving 5 "Tens" as the final representation. Again, the student only used the "Ten" blocks and did not use the "One" blocks. The student did not understand the value of the numerals or the value of the blocks.

The student was asked to show 123, 384, and 856 using Base Ten Blocks. For 123, the student showed one "Hundred" and said, "One", showed another "Hundred" and said, "Two", then showed a third "Hundred" and said, "Three hundreds". On 384, the student put down three "Hundreds" and said, "This is too hard". The pretest was concluded at this point.

The pretest revealed the student was not able to represent numbers between 1 and 999 using the Base Ten Blocks. Because of the student's difficulty with 
numbers from 1 to 100 , numbers greater than 100 were not used in the development of the IEP.

\subsection{Individualized Education Plan}

Instruction was provided to show a "fair trade" of ten "Ones" for one "Ten" at the beginning of the first lesson. The student counted ten "Ones", then placed the "Ten" block on top and beside the ten "Ones" to show that they represented the same number of blocks. The student showed base-ten block representations for numbers 1 to 100 with the aid of pictures. A place-value mat was used on which to lay the blocks. See Figure 2 below. The student and instructor counted the blocks for several numbers. For example on 28, tens were counted, "Ten, twenty", followed by counting the ones, "twentyone, twenty-two, twenty-three, twenty-four, twentyfive, etc.". During this lesson, the student had difficulty in counting by tens such as saying "fifteen" instead of fifty and saying "sixteen" instead of sixty.

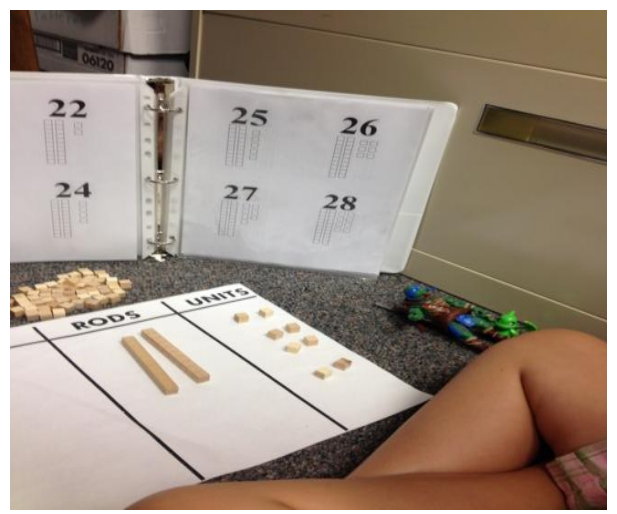

Figure 2. Representation using pictures

For the second lesson, the student showed the representations for numbers 1 to 100 using base-ten blocks without the use of pictures. The student counted aloud as the representations were shown. The student had difficulty in naming "forty-four", "fifty-five", and "sixty-six". The student also said "sixteen" instead of sixty; but did say the rest of the sixties correctly.

Numbers 1 to 100 were placed in a bag, for the third, fourth, and fifth lessons. The student or instructor drew a number from the bag then the student said the number, showed the representation using the base-ten blocks, and counted the blocks aloud.

During lesson three, the student drew the numbers 54, 35, 44, 21, 16, and 75 . On the first problem, the student began by counting using "One" blocks only. The student was then asked to use the "Ten" blocks and "One" blocks to represent 54. The student did not seem to understand so the representation for 54 was modeled, the picture from lesson one was shown and explained. The blocks were counted together, "Ten, twenty, thirty, forty, fifty, fifty-one, fifty-two, fifty-three, fifty-four." The student was able to name the five numbers and answer, "How many ones?" and "How many tens?" were in each number. The student had difficulty naming the number " 16 "; but counted from 1 to 16 with the aid of a Hundred Chart. The student was able to show the correct base-ten block representation for the five numbers on the placevalue chart. See Figure 3 below. The student had difficulty counting the blocks independently. In counting by tens the student counted, "Ten, twenty, thirty, forty, fifteen, sixteen, seventeen", when counting the "Ten" blocks in "75". The student is not able to count by tens then add on the ones independently.

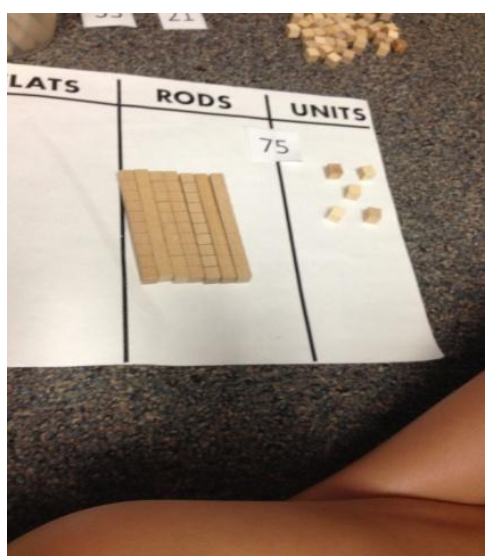

Figure 3. Representation for Seventy-Five

For lesson four, the student pointed to the numbers on the Hundred Chart and counted 1-100. For instruction, a hand-full of "One" blocks were placed on the place-value chart. The student correctly counted the blocks from 1-23. The "fair trade" concept was modeled and explained to the student. The student preferred the word "switched". The student drew the numbers 35, 15, 92, 45, and 25 for this lesson. The student was able to name each of the five numbers; but had difficulty with " 15 ". With the aid of the Hundred Chart, the student counted from 1 to 15 . The student showed the correct baseten block representation for each problem on the place-value chart. The student had difficulty counting the blocks by tens and ones; so they were counted together with the instructor.

On lesson five, the student drew the numbers 90 , $35,57,78$, and 12 . The number " 47 " was used for modeling and instruction. The student was able to name each number and show the correct base-ten block representation on the place-value chart. The student was able to count by tens and add on the ones for 35 and 57; but needed assistance with the other numbers. The student counted the 12 blocks by ones. 


\subsection{Posttest}

For the first part of the posttest, a hand-full of "One blocks" were given to the student. The student was able to count the blocks by ones and was able to display the base-ten block representation for the 32 blocks. The student was able to show the base-ten block representations for $24,46,13,33$, and 97 . The student was also asked to count the blocks. The student was able to count the blocks correctly by tens and then add on the ones except for ' 13 '. The student said, "Fourteen" for forty and said "eighteen" instead of eighty when counting the blocks in 97 . See Figure 4 below.

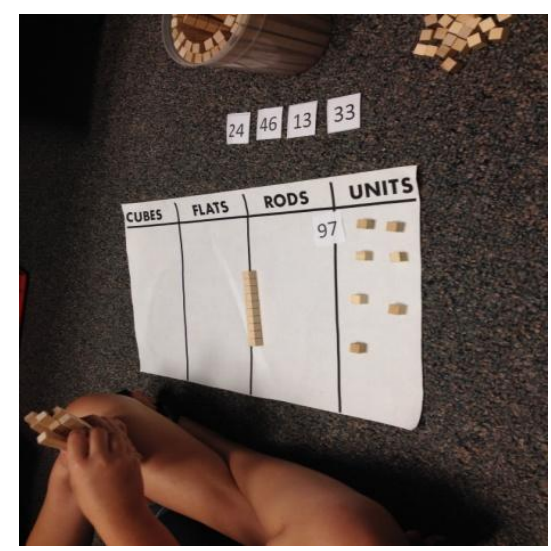

Figure 4. Posttest problem

The student was able to show the representations; but had difficulty in counting the blocks. A "Hundred Chart" was used during the fourth lesson and the student was able to count from 1 to 100 . The student had $80 \%$ mastery in naming random numbers from 1 to 100 and in using base-ten blocks to represent those numbers. After the study and a little more practice, the student should be ready to attempt numbers greater than 100 .

\section{Conclusions}

Based on the results of the pretest, the researchers diagnosed the student's level of understanding of mathematical place value at Level $2[4,5,6]$. After the five instructional sessions, the results of the posttest determined that the student's understanding of place value was at Level $4[4,5,6]$. The results will be provided to the student's classroom teacher in order that the student's needs may be more adequately addressed during the next school year.

\section{References}

[1] National Council of Teachers of Mathematics, Principles and Standards for School Mathematics, NCTM, Reston, Va, 2000, p. 78.

[2] Common Core State Standards Initiative, Preparing America's Students for College \& Career, Mathematics Standards, 2014, Grade 1 \& Grade 2.

[3] Cawley, J.F., R.S. Parmar, L. Lucas-Fusco, J.D. Kilian, and T.E. Foley, "Place value and mathematics for students with mild disabilities: Data and suggested practices", Learning Disabilities: A Contemporary Journal, Vol. 5 No. 1, 2007, pp. 21-39.

[4] Ross, S. The Development of Children's Place-Value Numeration Concepts in Grades Two through Five, 1986, Paper presented at the annual meeting of the American Educational Research Association, San Francisco, CA.

[5] Ross, S. "Parts, wholes and place-value: A developmental view", Arithmetic Teacher, Vol. 36 No. 6, 1989, pp. 47-51.

[6] Ross, S. "Children's acquisition of place-value numeration concepts: The roles of cognitive development and instruction", Focus on Learning Problems in Mathematics, Vol. 12 No. 1, 1990, pp. 1-17.

[7] Van De Walle, J.A., K.S. Karp, and J.M. BayWilliams, Elementary and Middle School Mathematics: Teaching Developmentally, Allyn \& Bacon, Boston, MA, 2010.

[8] Resnick, L., and S. Omanson. "Learning to Understand Arithmetic." Advances in Instructional Psychology (Vol. 3), edited by R. Glaser, LEA, Hillsdale, New Jersey, 1987.

[9] Miller, S.P. and P.J. Hudson, "Helping Students with Disabilities Understand What Mathematics Means", Teaching Exceptional Children, Vol. 39 No. 1, 2006, pp. 28-35.

[10] Parmar, R.S., R. Frazita, and J.F. Cawley, "Mathematics Assessment for Students with Mild Disabilities: An Exploration of Content Validity", Learning Disability Quarterly, Vol. 19, Spring 1996, pp. 127-136. 